\title{
Predication of life cycle cost of equipment base on unbiased grey Markov models
}

\author{
Yonghong Chen ${ }^{1, *}$, Ping $\mathrm{Hu}^{2}$, and Dong Zhang ${ }^{3}$ \\ ${ }^{1}$ College of Mechanical and Electrical Engineering, Wuhan Donghu University, Wuhan, China \\ ${ }^{2}$ College of Ships and Oceanography, Naval University of Engineering, Wuhan, China \\ ${ }^{3}$ Department of Power control, Naval Submarine Academy, Qingdao, China
}

Keywords: Life cycle cost, Unbiased grey model, Grey Markov models, Posterior difference method, Predication.

\begin{abstract}
Life cycle cost(LCC) is an important content of equipment integrated logistics support. While the LCC includes the whole life cycle of equipment from development, production, service and maintenance to retirement, in order to effectively manage and control the LCC and better develop integrated logistics support, it is necessary to analyze and predict it. The unbiased grey markov model(UGMM) was introduced into the LCC prediction in the paper, in order to check model accuracy, the posterior difference method(PDM) was used, also the influence by the number of state intervals in UGMM on the prediction accuracy is analyzed and studied. The result indicate that UGMM can be used to predict the LCC, also have the highest prediction accuracy comparing with unbiased grey model and grey separating model, and in order to ensure the prediction accuracy, the state interval should be divided according to the number of sequence.
\end{abstract}

\section{Introduction}

Life cycle cost(LCC) of equipment was first proposed by the U. S. Department of defense in the 1960s, it is defined as the sum of all costs paid for the demonstration, development, production, service, maintenance, support, and retirement of equipment within the life cycle, its main purpose is to reveal the law of the occurrence and development of LCC, so as to take effective methods to control it $[1,2,4]$. The control of LCC is one of the important contents of equipment integrated logistics support(ILS). The purpose of ILS is to minimize the LCC on the basis of ensuring the equipment integrity, so as to maximize the cost-effectiveness ratio of the equipment cost [3, 4]. As in [5], Li Hongtao studied the equipment selection of wind turbine system using the LCC model.

The methods of LCC predication are analogy estimation method, parameter estimation method and engineering evaluation method $[1,2,4]$. Parameter estimation method is be commonly used, which is not only suitable for the cost evaluation in the later stage of demonstration and early stage of development, but also can be used to verify the conclusions of other estimation methods [4]. Parameter estimation methods include: grey theory $[1,6]$,

\footnotetext{
*Corresponding author: 82746871@qq.com.cn
} 
principal component analysis [1,7], support vector machine method[1,8], neural network method [1,9] and fuzzy theory [10], etc.

Grey theory and Markov are widely used in all fields [11-15]. Base on previous research results $[11,12]$, this paper introduces unbiased grey markov model(UGMM) into LCC prediction and the results were checked by posterior difference method(PDM). At the same time, the influence of the number of state interval divisions on the prediction accuracy was studied.

\section{Unbiased gray Markov model}

\subsection{Unbiased grey model}

In order to improve the accuracy, the unbiased grey model(UGM)[11, 13, 14] was used. Its principle is:

Assume a observation time sequence of a certain behavior characteristic of the system is:

$$
x^{(0)}=\left\{x^{(0)}(1), x^{(0)}(2), \cdots, x^{(0)}(n)\right\},(n \geq 1)
$$

After an accumulation process on sequence $x^{(0)}$, a new sequence can be obtained.

$$
\begin{gathered}
x^{(1)}=\left\{x^{(1)}(1), x^{(1)}(2), \cdots, x^{(1)}(n)\right\},(n \geq 1) \\
\left\{\begin{array}{l}
x^{(1)}(1)=x^{(0)}(1) \\
x^{(1)}(2)=x^{(0)}(1)+x^{(0)}(2) \\
\cdots \\
x^{(1)}(n)=\sum_{i=1}^{n} x^{(0)}(i)
\end{array}\right.
\end{gathered}
$$

For the sequence $x^{(1)}$ with grey exponential law, the UGM [10-12] can be established, which is a first-order linear differential equation:

$$
d x^{(1)} / d t+A x^{(1)}=b
$$

In order to obtain the parameters $b$ and $A$, the matrices $B$ and $Y_{n}$ are constructed:

$$
B=\left[\begin{array}{cc}
-\frac{1}{2}\left(x^{(1)}(1)+x^{(1)}(2)\right) & 1 \\
-\frac{1}{2}\left(x^{(1)}(2)+x^{(1)}(3)\right) & 1 \\
\vdots & \vdots \\
-\frac{1}{2}\left(x^{(1)}(n-1)+x^{(1)}(n)\right) & 1
\end{array}\right], Y_{n}=\left[\begin{array}{c}
x^{(0)}(2) \\
x^{(0)}(3) \\
\vdots \\
x^{(0)}(n)
\end{array}\right]
$$

The least square method is used to estimate the values of parameters $\hat{a}$ and $\hat{u}$ of the first order linear differential as in Eq. 6. 


$$
\left[\begin{array}{ll}
\hat{a} & \hat{u}
\end{array}\right]^{T}=\left(B^{T} B\right)^{-1} B^{T} Y_{n}
$$

After calculate $\hat{a}$ and $\hat{u}$, the values of parameters $b$ and $A$ of UGM can be obtained by follow:

$$
b=\ln \frac{2-\hat{a}}{2+\hat{a}}, A=\frac{2 \hat{u}}{2+\hat{a}}
$$

Finally, the UGM of the sequence $x^{(0)}$ can be obtained and can be used to predict:

$$
\left\{\begin{array}{c}
\hat{x}^{(0)}(1)=x^{(0)}(1) \\
\hat{x}^{(0)}(k+1)=A e^{b k}, k=1,2,3, \cdots n-1
\end{array}\right.
$$

\subsection{More format Markov model}

Form Eq. 8, the residual sequence $z(k)$ will obtain, which:

$$
z(k)=x^{(0)}(k)-x^{(0)}(k)
$$

Taking the residual sequence $z(k)$ as a Markov chain [11, 14-17], according to the maximum and minimum values of the sequence $z(k)$, it can be divided into $m$ state intervals $I_{m}$, and the $m$ th state interval is labeled as state $E_{m}$, all of the residual of $z(k)$ have their labels. From time $k$ to next time $k+1$, the number of states $E_{m}$ transferred to $E_{m+1}$ in one step is count, and a $m \times m$ frequency matrix $\left(n_{i j}\right)_{m \times m}$ is obtained. Through the frequency matrix, the one-step state transition probability matrix can be obtained as follows:

$$
R=\left(p_{i j}\right)_{m \times m}=\left[\begin{array}{cccc}
p_{11} & p_{12} & \cdots & p_{1 m} \\
p_{21} & p_{22} & \cdots & p_{2 m} \\
\vdots & \vdots & \vdots & \vdots \\
p_{m 1} & p_{m 2} & \cdots & p_{m m}
\end{array}\right],\left(p_{i j}\right)_{m \times m}=\frac{\left(n_{i j}\right)_{m \times m}}{n_{i}}
$$

For example, if $E_{2}$ is the labeled state of $z(k)$, the frequency of state $E_{2}$ transfer to state $E_{1}$ in one step is $E_{21}$, and,

$$
E_{21}=n_{21}
$$

The frequency of state $E_{2}$ transfer to state $E_{i}$ in one step is $H$.

$$
n_{2}=H=\sum_{i=1}^{m} E_{2 i}
$$


So the value of $p_{21}$ is:

$$
p_{21}=\frac{n_{21}}{n_{2}}=\frac{E_{21}}{\sum_{i=1}^{m} E_{2 i}}
$$

If the initial state of a sequence $z(k)$ which divided according to the state intervals $I_{m}$ is $F^{(0)}$, after $t$-step transfer, the state became $F^{(t)}$ :

$$
F^{(t)}=F^{(0)} \times R^{(t)}(t \geq 1)
$$

Thus, the future state of the object is predicted, and the $t$ th step prediction value is:

$$
\hat{z}(k)=\sum_{i=1}^{m} F^{(t)} \times I
$$

which $I$ is the intermediate value matrix for dividing the interval. Of course, for different research objects, $I$ can also take different values according to the range of the state interval.

Combined with the above steps, the predicted value is:

$$
\hat{x}(k+1)=x^{(0)}(k)+\hat{z}(k)
$$

\subsection{Posterior difference method}

In the process of prediction, the PDM [17-20] is used to check the prediction accuracy of model. The principle of PDM is calculated as follows:

Original sequence mean value:

$$
\bar{x}^{(0)}=\frac{1}{N} \sum_{i=1}^{N} x^{(0)}(i)
$$

Absolute error mean value:

$$
\bar{e}=\frac{1}{N} \sum_{i=1}^{N}|e(i)|, \text { which } e(i)=x^{(0)}(i)-\hat{x}(i)
$$

Original sequence variance:

$$
S_{1}^{2}=\frac{1}{N} \sum_{i=1}^{N}\left(x^{(0)}(i)-\bar{x}^{(0)}\right)^{2}
$$

Absolute error variance:

$$
S_{2}^{2}=\frac{1}{N} \sum_{i=1}^{N}\left(e^{(0)}(i)-\bar{e}^{(0)}\right)^{2}
$$

Thus, the posterior difference ratio $C=S_{2} / S_{1}$ and small error frequency $P$ are defined to evaluate the model. which: 


$$
P=P\left\{|e(i)-\bar{e}| \leq 0.6745 S_{1}\right\}
$$

Generally, the smaller $C$ and the larger $P$ were indicates that the prediction model has a better fitness with the original sequence, and the model accuracy is higher [20], the relationship between $C, P$ and the prediction accuracy of the model is shown in Table 1.

Table 1. Value of $C, P$ and model prediction accuracy level [17].

\begin{tabular}{|c|c|l|}
\hline $\mathrm{C}$ & $\mathrm{P}$ & \multicolumn{1}{c|}{ Level description } \\
\hline $\mathrm{C}<0.35$ & $\mathrm{P}>0.95$ & The model prediction accuracy is high. \\
\hline $\mathrm{C}<0.50$ & $\mathrm{P}>0.80$ & The model prediction accuracy is acceptable. \\
\hline $\mathrm{C}<0.45$ & $\mathrm{P}>0.70$ & The prediction accuracy of the model barely meets the requirements. \\
\hline $\mathrm{C} \geq 0.45$ & $\mathrm{P} \leq 0.70$ & The model prediction accuracy cannot meet the requirements. \\
\hline
\end{tabular}

\section{Example}

As in ref. 6, from 1992 to 2001, the maintenance costs of equipment are:

$$
X=\{1.15,1.95,2.35,2.70,3.08,3.50,3.89,4.69,6.50,8.19\}
$$

which is shown in Table 2.

\begin{tabular}{|c|c|c|c|c|c|c|c|c|c|c|c|c|}
\hline Year & 1992 & 1993 & 1994 & 1995 & 1996 & 1997 & 1998 & 1999 & 2000 & 2001 & $\mathrm{C}$ & $\mathrm{P}$ \\
\hline Cost[million] & 1. 15 & 1.95 & 2. 35 & 2. 70 & 3.08 & 3. 50 & 3.89 & 4. 69 & 6.50 & 8. 19 & - & - \\
\hline $\begin{array}{c}\text { Grey } \\
\text { separating } \\
\text { model[6] }\end{array}$ & $\begin{array}{c}1 . \\
1815\end{array}$ & $\begin{array}{c}1 . \\
8311\end{array}$ & $\begin{array}{c}1 . \\
9322\end{array}$ & $\begin{array}{c}2 . \\
3374\end{array}$ & $\begin{array}{c}2 . \\
8282\end{array}$ & $\begin{array}{c}3 . \\
4228\end{array}$ & $\begin{array}{c}4 . \\
1434\end{array}$ & $\begin{array}{c}5 . \\
0169\end{array}$ & $\begin{array}{c}6 . \\
0759\end{array}$ & $\begin{array}{c}7 . \\
3600\end{array}$ & $\begin{array}{c}0 . \\
1609\end{array}$ & 1 \\
\hline UGM & 1. 150 & $\begin{array}{c}1 . \\
6935\end{array}$ & $\begin{array}{c}2 . \\
0489\end{array}$ & $\begin{array}{c}2 . \\
4790\end{array}$ & $\begin{array}{c}2 . \\
9993\end{array}$ & $\begin{array}{c}3 . \\
6288\end{array}$ & $\begin{array}{c}4 . \\
3904\end{array}$ & $\begin{array}{c}5 . \\
3119\end{array}$ & $\begin{array}{c}6 . \\
4269\end{array}$ & $\begin{array}{c}7 . \\
7758\end{array}$ & $\begin{array}{c}0 . \\
1580\end{array}$ & 1 \\
\hline UGMM3 & 1. 150 & $\begin{array}{c}1 . \\
5896\end{array}$ & $\begin{array}{c}2 . \\
1246\end{array}$ & $\begin{array}{c}2 . \\
5713\end{array}$ & $\begin{array}{c}3 . \\
0931\end{array}$ & $\begin{array}{c}3 . \\
7225\end{array}$ & $\begin{array}{c}4 . \\
4839\end{array}$ & $\begin{array}{c}5 . \\
4054\end{array}$ & $\begin{array}{c}6 . \\
5204\end{array}$ & $\begin{array}{c}7 . \\
8693\end{array}$ & $\begin{array}{c}0 . \\
1686\end{array}$ & 1 \\
\hline UGMM4 & 1. 150 & $\begin{array}{c}1 . \\
8055\end{array}$ & $\begin{array}{c}2 . \\
1177\end{array}$ & $\begin{array}{c}2 . \\
5590\end{array}$ & $\begin{array}{c}3 . \\
0713\end{array}$ & $\begin{array}{c}3 . \\
6856\end{array}$ & $\begin{array}{c}4 . \\
4382\end{array}$ & $\begin{array}{c}5 . \\
3578\end{array}$ & $\begin{array}{c}6 . \\
4727\end{array}$ & $\begin{array}{c}7 . \\
8226\end{array}$ & $\begin{array}{c}0 . \\
1539\end{array}$ & 1 \\
\hline UGMM5 & 1. 150 & $\begin{array}{c}1 . \\
8659\end{array}$ & $\begin{array}{c}2 . \\
1523\end{array}$ & $\begin{array}{c}2 . \\
5590\end{array}$ & $\begin{array}{c}3 . \\
1115\end{array}$ & $\begin{array}{c}3 . \\
7246\end{array}$ & $\begin{array}{c}4 . \\
4772\end{array}$ & $\begin{array}{c}5 . \\
3966\end{array}$ & $\begin{array}{c}6 . \\
5115\end{array}$ & $\begin{array}{c}7 . \\
8611\end{array}$ & $\begin{array}{c}0 . \\
1551\end{array}$ & 1 \\
\hline
\end{tabular}

Table 2. Calculation results of three prediction models.

NOTE: UGMM3, UGMM4 and UGMM5 represents the unbiased grey Markov model with 3, 4 and 5 state intervals respectively.

\subsection{Unbiased grey Model calculation}

As in Eq. 2 , Eq. 3, the new accumulation sequence is:

$$
X_{1}=\{1.15,3.10,5.45,8.15,11.23,14.73,18.62,23.31,29.81,38.00\}
$$

As in Eq. 5, the matrices $B$ and $Y_{n}$ can be calculated in follow: 


$$
B=\left[\begin{array}{ll}
-2.125 & 1 \\
-4.275 & 1 \\
-6.800 & 1 \\
-9.690 & 1 \\
-12.980 & 1 \\
-16.675 & 1 \\
-20.965 & 1 \\
-26.560 & 1 \\
-33.905 & 1
\end{array}\right], Y_{n}=\left[\begin{array}{l}
1.95 \\
2.35 \\
2.70 \\
3.08 \\
3.50 \\
3.89 \\
4.69 \\
6.50 \\
8.19
\end{array}\right]
$$

As in Eq. 6 , Eq. 7, the parameters in UGM can be calculated as: $\hat{a}=-0.1900, \hat{u}=1.2667$, $b=0.1905, A=1.3997$.

Then the UGM is:

$$
\left\{\begin{array}{c}
\hat{x^{(0)}}(1)=1.150 \\
\hat{x^{(0)}}(k+1)=1.3997 e^{0.1905 k}, k=1,2, \cdots, 9
\end{array}\right.
$$

$-\hat{a}$ is less than 0.3 , which also indicates that the model can be used as a medium and long-term predication [19], and the prediction results are shown in Table 2.

\subsection{Markov model calculation}

As in Eq. 9, the residual sequence is:

$$
z(k)=\{0,0.2565,0.3011,0.2210,0.0807,-0.1288,-0.5004,-0.6219,0.0731,0.4142\}
$$

In the $z(k)$, the maximum value is 0.4142 and the minimum value is -0.6219 . According to the range, it can be divided into four states, and the results were be note as UGMM4. The interval of each state which divided is show in Table 3. Of course, it can also be divided into other states.

Table 3. The states and the interval of each state

\begin{tabular}{|c|c|c|c|c|}
\hline States & E1 & E2 & E3 & E4 \\
\hline Interval of each state & {$[-0.6219-0.3629]$} & {$[-0.3629-0.1039]$} & {$[-0.10390 .1552]$} & {$[0.15520 .4142]$} \\
\hline
\end{tabular}

The state division of $z(k)$ is shown in Table 4 .

Table 4. States of residual sequence value

\begin{tabular}{|c|c|c|c|c|c|c|c|c|c|c|}
\hline $\begin{array}{c}\text { Residual } \\
\text { value }\end{array}$ & 0 & 0. & 0. & 0. & 0. & -0. & -0. & -0. & 0. & 0. \\
\hline States & E3 & E4 & E4 & E4 & E3 & E2 & E1 & E1 & E3 & E4 \\
\hline
\end{tabular}

According to Table 4, the frequency of transitions from state E1 to state E1 in one step is 1, which is abbreviated as E11 $=1$, and the same reason, E13=1, E12=E14=0, then, 


$$
p_{11}=\frac{E_{11}}{E_{11}+E_{12}+E_{13}+E_{14}}=\frac{1}{1+0+1+0}=0.5
$$

As in Eq. 11, Eq. 12 and Eq. 13, the one-step transition matrix and median matrix can be calculated as:

$$
R^{(1)}=\left[\begin{array}{cccc}
0.5 & 0 & 0.5 & 0 \\
1 & 0 & 0 & 0 \\
0 & 0.3333 & 0 & 0.6667 \\
0 & 0 & 0.3333 & 0.6667
\end{array}\right] \quad I=\left[\begin{array}{c}
-0.4924 \\
-0.2334 \\
0.0257 \\
0.2847
\end{array}\right]
$$

E. $g$, the cost of 1993 will be predicted by the cost of 1992. As in Table 4, the state of the residual in 1992 is E3, so the initial state interval $F^{(0)}$ is $[0,0,1,0]$, as in Eq. 14, Eq. 15 and Eq, 28, the residual cost of 1993 is:

$$
\hat{z}(2)=S^{(0)} R(1) I_{10}=[0,0,1,0] \times\left[\begin{array}{cccc}
0.5 & 0 & 0.5 & 0 \\
1 & 0 & 0 & 0 \\
0 & 0.3333 & 0 & 0.6667 \\
0 & 0 & 0.3333 & 0.6667
\end{array}\right] \times\left[\begin{array}{c}
-0.4924 \\
-0.2334 \\
0.0257 \\
0.2847
\end{array}\right]=0.1120
$$

As in Eq. 9, Eq, 25, Eq. 29 and Table. 2, the cost of 1993 is:

$$
\hat{x}(2)=\hat{x}(2)+\hat{z}(2)=1.6935+0.1120=1.8055
$$

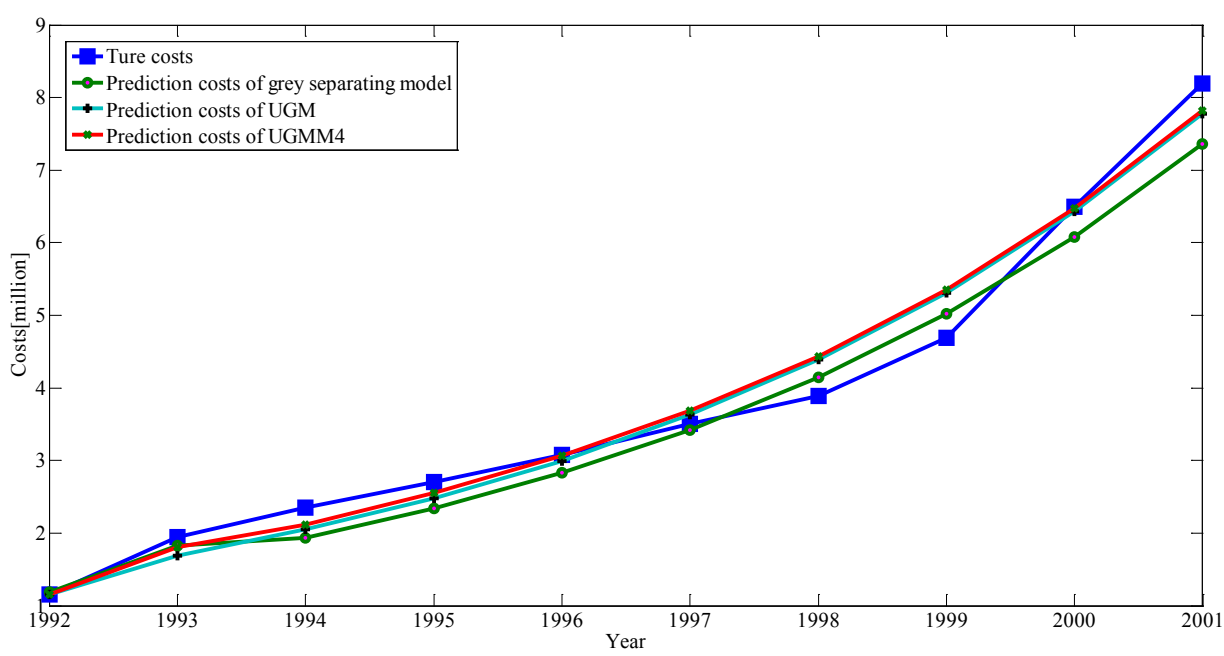

Fig. 1. Comparison of prediction results of each prediction method.

Similarly, in the same steps, the residuals of costs in various years can be predicted. The comparison between the prediction results is shown in Table. 2, and the diagram is shown in Fig. 1.

\subsection{Analysis of state interval division}

In order to analyze the influence of state interval division on prediction accuracy, the residual state interval is divided into three and five for comparison.

State was be divided into 3. The interval of each state which divided is show in Table 5. 
Table 5. The states and the interval of each state.

\begin{tabular}{|c|c|c|c|}
\hline States & E1 & E2 & E3 \\
\hline Interval of each state & {$[-0.6219-0.2766]$} & {$[-0.27660 .0688]$} & {$[0.06880 .4142]$} \\
\hline
\end{tabular}

The one-step transfer matrix and the intermediate value matrix are calculated as follows:

$$
R^{(1)}=\left[\begin{array}{ccc}
0.5 & 0 & 0.5 \\
0.5 & 0 & 0.5 \\
0 & 0.2 & 0.8
\end{array}\right], I_{10}=\left[\begin{array}{c}
-0.4492 \\
-0.1039 \\
0.2415
\end{array}\right]
$$

The predicted results and value of $C$ and $P$ of PDM are shown in Table 2, and the results were be note as UGMM3.

State was be divided into 5. The interval of each state which divided is show in Table 6 .

Table 6. The states and the interval of each state.

\begin{tabular}{|c|l|l|l|l|c|}
\hline States & \multicolumn{1}{|c|}{ E1 } & \multicolumn{1}{|c|}{ E2 } & \multicolumn{1}{|c|}{ E3 } & \multicolumn{1}{|c|}{ E4 } & E5 \\
\hline $\begin{array}{c}\text { Interval of } \\
\text { each state }\end{array}$ & $\begin{array}{l}{[-0.6219-0 .} \\
4147]\end{array}$ & $\begin{array}{l}{[-0.4147-0 .} \\
2075]\end{array}$ & $\begin{array}{l}{[-0.2075-0 .} \\
0002\end{array}$ & $\begin{array}{l}{[-0 .} \\
2070]\end{array}$ & $\begin{array}{c}0.2002 \\
2070 .\end{array}$ \\
\hline
\end{tabular}

The one-step transfer matrix and the intermediate value matrix are calculated as follows:

$$
R^{(1)}=\left[\begin{array}{ccccc}
0.5 & 0 & 0 & 0.5 & 0 \\
0 & 0 & 0 & 0 & 0 \\
1 & 0 & 0 & 0 & 0 \\
0 & 0 & 0.3333 & 0 & 0.6667 \\
0 & 0 & 0 & 0.3333 & 0.6667
\end{array}\right], I_{10}=\left[\begin{array}{c}
-0.5183 \\
-0.3111 \\
-0.1039 \\
0.1034 \\
0.3106
\end{array}\right]
$$

The predicted results and value of $C$ and $P$ of PDM are shown in Table 2, and the results were be note as UGMM5.

\subsection{Results}

As in Table 1 and Table 2, the value of $P$ are equal to 1 , greater than 0.95 . The value of $C$ are $0.1609,0.1580$ and 0.1539 , all of them are less than 0.35 , and the $C$ of UGMM have the least value, it indicated that the three models can be used to LCC prediction, and the UGMM has the highest prediction accuracy. Also from Fig. 1, UGMM has the best fitness with true costs.

The calculation results show that the prediction accuracy of UGMM3 and UGMM5 are lower than that of UGMM4. Theoretically, the more the state interval is divided, the more accurately the sequence state transition is described, and the higher the accuracy of the prediction result obtained. However, limited by the number of data in the sample sequence, the more the state interval is divided, the accuracy will decrease.

\section{Conclusion}

In this paper, the LCC prediction was studied which based on UGMM, results indicated UGMM can be used in LLC prediction, and prediction accuracy is high. Also the prediction result not only can provide important support decision for the integrated logistics support of 
equipment, but also has great significance for further improving the cost-effectiveness ratio of equipment costs.

\section{References}

1. Liu Xiao-dong, Life cycle cost analysis and control of equipment, National defence industry press, Beijing, 2008.

2. Huang Xun-jiang, Life cycle cost evaluation and management of equipment with life cycle as independent variable, Science press, Beijing, 2012.

3. General armament department of PLA, General requirements for materiel integrated logistics support:GJB3872-99, General armament department of PLA, Beijing, 1999.

4. LIU Peng, DONG Zhen-qi, QU Yan, Life cycle cost analysis and optimization model of weapon and equipment system, Journal of Sichuan ordnance. 33(2012)57-59.

5. LI Hong-tao. Application of life cycle cost theory in selection of speed control equipment for fan system, 2018's china cement network annual conference. (2018):29-32.

6. Meng Ke, ZHANG Bo. Analysis for life cycle cost of equipment using grey separating model, Fire control \& command control. 36(2011)79-84.

7. ZHANG Xiao-hai, JIN Jia-shan, GENG Jun-bao, Modeling for life cycle cost by using DEA to optimizing principal components regression, Journal of naval university of engineering. 23(2011)32-36.

8. LUO Wei, XIAO Shang-qin. Ship LCC based on improved SVM algorithm. Computer and digital engineering. 45(2017) 287-290.

9. Robert Savić, Uwe K. Rakowsky. A neuro-fuzzy reliability optimization method considering life cycle costs, Probabilistic Safety Assessment and Management. (2004)1388-1394.

10. LIANG Qing-wei, SONG Bao-wei, WU Chao-hui. Life cycle cost modeling of fuzzy least squares regression for weapon system, Fire control \& command control. 31(2006)45-47.

11. CHEN Yong-hong, ZHANG Da-fa, CHEN Deng-ke, Prediction on corrosion rate of pipe in nuclear power system based on optimized grey theory, Atomic energy science and technology. 41(2007)707-710.

12. CHEN Yong-hong, ZHANG Da-fa, WANG Yue-min. Prediction of pipeline corrosion rate based on grey markov models, Nuclear power engineering. 30(2009)95-98.

13. XU Gang-nian, WANG You-zhi, WANG Shi-min, Main girder deformation prediction model with improved unequal interval weight gray correction, Journal of Sichuan university . 50(2018)91-99.

14. Ma Guo-feng, Zhou Qiao-qiao, Research on adjustment model of PPP project concession period based on grey markov forecast, Science and technology management research. 38(2018)224-232.

15. ZHANG Xi-Lai, ZHAO Jian-Hui, CAI Bo. Prediction model with dynamic adjustment for single time series of PM2. 5, Acta automatica sinica. 44(2018)1790-1798.

16. CHEN De-yi, YAN Quan-sheng, Prediction research of special-shaped arch bridge arch-rib spatial alignment based on markov model, Journal of south china university of technology. 46(2018)41-47. 
17. ZHANG Jing-yi, LIAN Meng, GONG Jie, Combination forecasting of POL consumption based on time series and grey theory, Journal of ordnance equipment engineering. 39(2018)132-135.

18. CHEN Jia-qi, SI Da-xiong, DING Lei, Application of DNGM $(1,1)$ prediction model in prediction of foundation pit water level change, Journal of Langfang normal university. 19(2019)90-93.

19. FU Ze-qiang, SUN Qi-hong, CAI Yun-long, Research on forecasting model of forest fire based on grey-system theory, Scientia silvae sinicae. 38(2002)95-100.

20. LIN Yun, ZHANG Rong-hui, WANG Yue-neng. Modern statistical analysis methods, Zhejiang university press, Hangzhou, 1991. 